\title{
Discussion: Role of cement content in specifications for concrete durability: aggregate type influences
}

\author{
R. K. Dhir, M. J. McCarthy, P. A. J. Tittle and S. Zhou
}

\section{A. Clear, British Cement Association, UK}

The results of the research reported by Prof. Dhir and the Dundee Concrete Technology Unit should be of considerable interest to those involved with the design and construction of durable structures, as well as the manufacturers of cement and concrete. It is evident that the authors establish the importance of achieving a concrete with a 'closed structure' and the importance of aggregate quality to concrete durability.

However, the important aspects of closed structure and aggregate quality may be overlooked due to the presentation of the conclusions which state that reducing the cement content at a given w/c ratio increases strength and improves absorption and permeability. Their conclusions appear somewhat remiss in that they omit a clear statement that these results were only achieved by replacing a proportion of cement with an equal proportion by mass of a very fine limestone powder.

At a surface area reported as $1600 \mathrm{~m}^{2} / \mathrm{kg}$ the limestone powder is nearly four times as fine as the CEM I which it replaces. As reported this fine limestone powder is used in conjunction with a superplasticising admixture to achieve practical requirements. To most engineers the use of such materials would be regarded as worth some mention in the conclusions or summary. The omission of these important details in the conclusion could give the unwary reader the impression that the fine limestone powder is just acting as a 'filler', being described as a filler aggregate in accordance with BS EN $12620 .{ }^{12}$ From the results provided it is evident that where increasing proportions of CEM I are replaced with the fine limestone powder in conjunction with increasing percentages of superplasticiser, then strength are increased. The combined practical observation is that increasing concrete strength improves durability properties such as absorption and permeability, and this should be prominently reported.

A problem with any practical application of the research work is that introducing an additional requirement for the type and amount of fine filler or powder increases the complexity of concrete specification. The current approach of specifying a minimum amount of cement provides a simple, practical, readily measured and robust method of achieving the desired 'closed structure' and should not be abandoned lightly.

The influence of aggregate properties on concrete durability is interesting and confirms other work at Dundee sponsored by the British Cement Association. ${ }^{29}$ The authors suggest that specifications could include specific restrictions on aggregate absorption. Once again though, this would increase the complexity of specifications and is likely to be resisted by the aggregate producers. Given the relationship between high aggregate absorption (porosity) and reduced concrete strength, a more practical approach is the specification of a minimum concrete strength class as seen in most current concrete specification guidance. ${ }^{30}$ This acts as an indirect control on the use of highly absorptive aggregates in structures where durability is of particular importance.

Until a practical way of moving away from prescriptive specification to performance-based specification of concrete can be devised, the current approach of placing limits on minimum cement content, maximum $\mathrm{w} / \mathrm{c}$ ratio and minimum concrete strength class, provides a simple and practical means of ensuring durability and should be retained.

\section{Authors' reply}

The authors would like to thank Dr Clear for his written contribution to the paper. As mentioned, this work, along with that published in the other papers and the report describing the project $^{4,6,31}$ establishes the importance of achieving a "closed structure' and of the role of aggregate quality and cement type on most aspects of concrete durability. However, it is important to note that this is within the framework of a study concerned with the role of cement content on durability specifications. With regard to these points it should be reiterated that: equivalent or improved performance could be achieved for many properties with the use of cement/limestone filler compared to that of cement alone, bringing into question the need for the minimum cement content requirement in standards; that in general, the effects of cement content were observed across the range of aggregate and cement types tested for most properties; and that aggregate properties and cement type had a greater impact on many aspects of performance than changing cement content at a given w/c ratio. As noted in the discussion, the above is based on the use of limestone filler that was finer than most of the cement constituents it replaced.

Concern is expressed about the abstract and the conclusions, in terms of their lack of coverage of the use of limestone filler in 
conjunction with superplasticising admixture in the test concretes. However, the paper states in the abstract that, "As for the first paper, the reported work was carried out within a framework of mix adjustments, required to produce practical concretes, that is, with the inclusion of filler and superplasticising admixture' and also in the preamble to the conclusions, 'It should be noted that in examining the effect of cement content, other adjustments were made to the concrete mixes, in order that they satisfied practical requirements, for example workability, fines content and yield'. Reference to the inclusion of filler or maintaining the fines content and the use of superplasticising admixture were also made in several other sections of the paper, including sections 2, 3.2., 4, 6 and 8. Given the above, it is difficult to see how this point could have received greater emphasis, without undue repetition.

The authors agree that strength can be an indicator of durability, but only for a given set of materials. Indeed, previous work at Dundee (for example see Fig. 9), has shown that: for a given compressive strength a range of performances were obtained for absorption in concrete with different cements (conforming to BS EN 197-1; ${ }^{11}$ for various Portland cement (PC)/fly ash combinations different chloride diffusion coefficients were found at specific concrete strengths; and for PC/fly ash grouts in magnesium sulfate solution, least expansion was noted with increasing fly ash content and reducing strength. The latter two examples highlight the importance of the cement chemistry on these processes. Thus the statement 'increasing concrete strength improves durability properties' can be very misleading. The authors would recommend that given the range of cement types available in BS EN 197-1, relating strength to durability should now be avoided.

As noted in the paper, reducing the cement content and associated changes to the mix causes, or may cause, a number of effects that influence performance, including: reduced cement paste and increased aggregate contents; enhanced cement paste-aggregate interface, with less bleeding; increased availability of nucleation sites for cement hydration and packing of solids, through the inclusion of limestone; more effective dispersion of cement flocs, through the use of superplasticising admixture; and reduced chemical binding capacity. Coverage of the impact of these and other factors on the various properties tested and how the trends observed compare with the related literature was considered to be of most importance in reviewing the test results, rather than the 'prominent reporting' of concrete strength, suggested.

Given the factors associated with aggregate that influence concrete strength and the absorption levels noted in this study at which concrete durability performance may be affected by aggregate (that is around 3.0\%), it is questionable whether "the specification of a minimum concrete strength class' would be 'a more practical approach' to covering the effect of aggregate. For example, it may be possible to have aggregate with absorption properties that have implications for durability, but which concrete strength measurements are not sensitive to. As suggested in the paper, a direct measure of this property of aggregate would appear to be a more reliable indicator of likely performance in concrete for aggressive conditions.

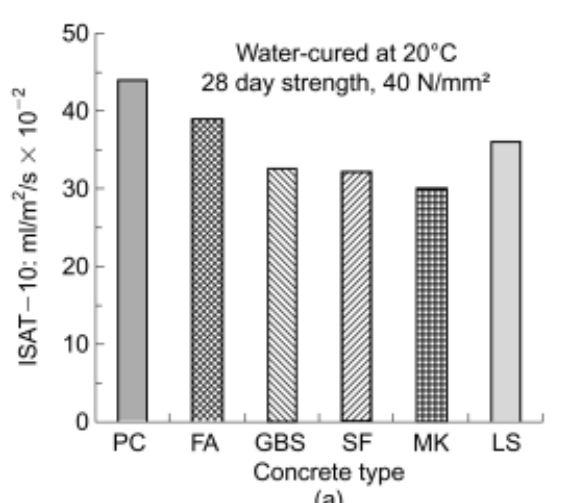

(a)

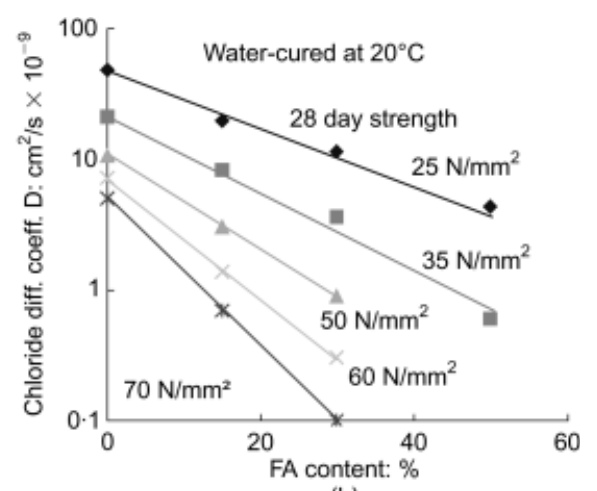

(b)

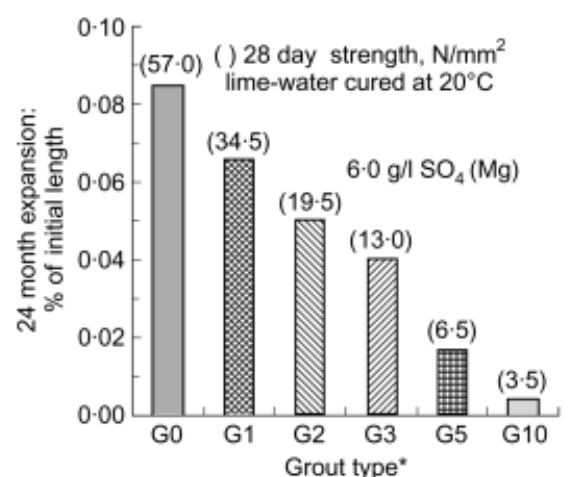

(c)

Fig. 9. Effect of cement type/combination on: (a) absorption; ${ }^{32}$ (b) chloride diffustion ${ }^{33}$ of concrete; (c) sulfate expansion of grout ${ }^{34}$ (*water/solids ratio $=0.4$ for all grouts, PC:FA; G0 $=$ $\mathrm{I}: 0, \mathrm{GI}=\mathrm{I}: \mathrm{I}, \mathrm{G} 2=\mathrm{I}: 2$, etc)

We agree that additional materials and separating aggregates into different classes would increase the complexity of specifications. However, if consideration is given to the changes in exposure classes and durability specifications between BS $5328^{8}$ and BS EN 206/BS 8500, ${ }^{1,2}$ the same applies. Although the new standard is more complex, it has improved the situation. Clearly, it is the effective and efficient use of materials that should be the important issue, balanced against what can be practically achieved, rather than what is simple. Furthermore, the authors would encourage the appropriate use of materials being made to push forward the sustainable construction agenda.

The authors would add that in publishing their work, they hope that it provokes thought and debate and contributes to 
the improvement of practices. At the end of the day, it is up to others to decide whether and how it should be used or applied in practice. Indeed, the work since its completion has been presented to, and discussed by, the relevant British Standards Concrete Committee. Finally, we would suggest that anybody seriously examining the work would be likely to go beyond the abstract and conclusions of a single paper to base any decisions on and would check the details in the other parts of the paper, our other publications ${ }^{4,6,31}$ and in the wider technical literature.

\section{REFERENCES}

29. Price W. F., Jones M. R., Ting S. C. and DHIR R. K. Effect of aggregate porosity on chloride ingress into concrete.

Proceedings of the International Symposium on the Role of Concrete in Sustainable Development (DHIR R. K., NEWLANDS M. D. and PAine K. A. (eds)). 2003, Dundee, 287-298.
30. BRITISH STANDARDS InSTITUTION. Concrete-Complementary British Standard to BS EN 206-1. Part 1. Method of Specifying and Guidance for the Specifier. BSI, London, 2002, BS 8500.

31. DhiR R. K., TitTle P. A. J. and McCARTHY M. J. Role of Cement Content in the Specification for Concrete Durability. BSI Research contract 33/3/16 (CC1629), 2001.

32. DhiR R. K., Chaipanich A and Williamson G. Use of Unfamiliar Cements to ENV 197-1 in Concrete. Concrete Technology Unit Report /1098, Dundee, 1999.

33. DHIR R. K. and BYARS E. A. PFA concrete: chloride diffusion rates. Magazine of Concrete Research, 1993, 45, No. 163, 1-9.

34. MCCARThy M. J., DhIR R. K. and Jones M. R. Benchmarking PFA grouts for magnesium sulfate exposures. Materials and Structures, 1998, 31, No. 103, 335-342. 